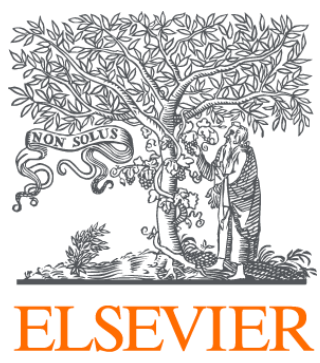

Since January 2020 Elsevier has created a COVID-19 resource centre with free information in English and Mandarin on the novel coronavirus COVID-

19. The COVID-19 resource centre is hosted on Elsevier Connect, the company's public news and information website.

Elsevier hereby grants permission to make all its COVID-19-related research that is available on the COVID-19 resource centre - including this research content - immediately available in PubMed Central and other publicly funded repositories, such as the WHO COVID database with rights for unrestricted research re-use and analyses in any form or by any means with acknowledgement of the original source. These permissions are granted for free by Elsevier for as long as the COVID-19 resource centre remains active. 


\title{
Review
}

\section{Clinical virology in real time}

\author{
Hubert G.M. Niesters * \\ Department of Virology, Erasmus MC, University Medical Center Rotterdam, Dr Molewaterplein 40, 3015 GD Rotterdam, The \\ Netherlands
}

\begin{abstract}
The ability to detect nucleic acids has had and still has a major impact on diagnostics in clinical virology. Both quantitative and qualitative techniques, whether signal or target amplification based systems, are currently used routinely in most if not all virology laboratories. Technological improvements, from automated sample isolation to real time amplification technology, have given the ability to develop and introduce systems for most viruses of clinical interest, and to obtain clinical relevant information needed for optimal antiviral treatment options. Both polymerase chain reaction (PCR) and nucleic acid sequence-based amplification (NASBA) can currently be used together with real time detection to generate results in a short turn-around time and to determine whether variants relevant for antiviral resistance are present. These new technologies enable the introduction of an individual patient disease management concept. Within our clinical setting, we have introduced this e.g. for quantitative detection of Epstein-Barr Virus (EBV) in T-dell depleted allogeneic stem cell transplant patients. This enabled us to develop models for pre-emptive anti B-cell immunotherapy for EBV reactivation, thereby effectively reducing not the incidence of EBV-lymphoproliferative disease but the virus related mortality. Furthermore, additional clinically relevant viruses can now easily be detected simultaneously. It also becomes more feasible to introduce molecular testing for those viruses that can easily be detected using classical virological methods, like culture techniques or antigen detection. Prospective studies are needed to evaluate the clinical importance of the additional positive samples detected. It should however be made clear that a complete exchange of technologies is unlikely to occur, and that some complementary technologies should stay operational enabling the discovery of new viruses. The implementation of these molecular diagnostic technologies furthermore warrants the use and introduction of standardized materials as well as participation in international quality control programs. Finally, the use of an internal control throughout the whole procedure not only ensures the accuracy of the results generated, but also is necessary to enable precise quantification of these results and to determine detection thresholds more accurately. Since so many targets do have clinical implications, laboratories might prefer to use universal internal controls before the in-house developed assays should be introduced in clinical virology.
\end{abstract}

(C) 2002 Elsevier Science B.V. All rights reserved.

Keywords: Disease management; Quantitative DNA assays; Real time detection; Standardization

* Tel.: +31-10-463-3431; fax: +31-10-463-3441

E-mail address: niesters@viro.fgg.eur.nl (H.G.M. Niesters).

\section{Introduction}

Several achievements have been made during the last decade enabling the sensitive detection and characterization of viral nucleic acids. Amplifica- 
Table 1

Bottlenecks in molecular diagnostics

\begin{tabular}{ll}
\hline Problem identified & Possible solution \\
\hline Quantitative technologies & Real time amplification technologies \\
Internal and external control & Well defined universal internal controls; \\
& Quality control programs \\
Sample preparation still matrix dependent & New extraction technologies \\
Hands-on time and turn-around time results & Automation \\
Commercially interesting viruses vs. viruses of no commercial interest & Well characterized home-brew assays \\
\hline
\end{tabular}

tion technologies, like polymerase chain reaction (PCR) and nucleic acid sequence-based amplification (NASBA) make the amplification of in principle any target of interest, possible. Furthermore, technological improvements in sequence detection systems enable the fully characterization of a virus, and to determine for instance the subtype, genotype, variants, mutants, and genotypic resistance patterns. The implementation of nucleic acid technology into routine diagnostics has made a great step forward with the introduction of real time technologies, which makes the detection of amplified products relatively easy (Niesters, 2001; Mackay et al., 2002). Furthermore, this technology is able to quantify target nucleic acids in a single sample over a larger dynamic range than most other quantitative technologies, although qualitative detection is of course also possible. Since both amplification and detection can currently be performed automatically, the most labor intensive and critical step remaining is the efficient extraction of nucleic acids from different clinical samples.

A second achievement in clinical virology is the increasing number of antiviral strategies possible. Not only for human immunodeficiency virus type 1 (HIV-1) but also for viruses like EBV and enteroviruses. These new antiviral strategies can however only be used successfully in combination with an optimal diagnostic strategy, in which the turn-around time to generate results should and must be relatively short. Furthermore, based on

Table 2

Commercially available assays vs. assays not-commercially available in clinical virology: targets of interest

Commercially interesting targets

Human immunodeficiency virus type 1

Hepatitis B virus

Hepatitis $\mathrm{C}$ virus

Cytomegalovirus

Human papilloma virus
In house to be developed (important) targets

Human immunodeficiency virus type 2

EBV

Herpes simplex virus type 1 and 2

Cytomegalovirus

Herpesvirus type 6

Varicella zoster virus

Enterovirus

Rhinovirus

Influenza virus

Coronavirus

Respiratory syncytium virus

Human metapneumovirus

Adenovirus

Parvovirus B19

Astrovirus

Calicivirus 
established risk factors, these strategies should be employed in a disease management concept, in which an integrated approach is anticipated with an optimal clinical and economical outcome.

\section{Bottlenecks in molecular diagnostics}

There are however a number of problems that need to be solved before molecular diagnostics should really be implemented routinely (Table 1). First, it is well recognized that for the clinical laboratory commercially standardized assays are available for a limited number of viral targets only. And it is unlikely that the number of target viruses will increase rapidly in the near future. However, it should be emphasized that there is a large and growing list of viruses for which the implementation and use of these nucleic acid technologies are advantageous. In Table 2, a tentative list of (what I call) commercially interesting viruses versus viral targets with limited commercial interest is given.

The second bottleneck is the easy and reproducible isolation of all nucleic acids (both RNA and DNA) from several clinical specimens. Many open systems are currently available, however, the need for an (fully) automated system with a high reliability is essential for complete implementation of nucleic acid detection in a day-to-day clinical virological setting. Furthermore, this will enable the laboratory to generate results with a short turn-around time, which is essential for patient disease management. It must however be mentioned that only limited information is available indicating the functionality of the available instrumentation in a diagnostic setting

The third bottleneck deals with standardization and quality control programs. It has been known since the early 1990s that one of the greatest hurdles to overcome in molecular technologies are false-positivity due to contamination, and falsenegativity due to the great difference in sensitivity of in most cases, home-brew assays (Quint et al., 1995; Schuurman et al., 1996; Zaaijer et al., 1993). Furthermore, differences in detecting all genotypes equally of e.g. HIV-1 or hepatitis C virus (HCV) with the same amplification efficiency have also been reported (Damen et al., 1996; Zaaijer et al.,
1994). Programs within Europe have been initiated and have indeed shown that there is a need for obtaining more standardized material and the need to participate in these programs (ValentineThon et al., 2001; van Vliet et al., 2001). A successor of one of these initiatives is called Quality Control for Molecular Diagnostics (QCMD; http://www.qcmd.org) endorsed by the European Society for Clinical Virology (ESCV) and the European Society for Microbiology and Infectious Disease (ESCMID) which starts to provide these quality control programs for an increasing number of viral targets, whether commercially interesting or not. Asides the need for a well defined quality control program, there is still the lack of standardization of quantitative assays, mainly due to the fact that standardization is limited to a select number of blood borne viruses, like HIV-1, hepatitis B virus (HBV) and HCV, for which internationally accepted World Health Organization (WHO) standards are made available (Saldanha et al., 1999, 2001). These standards are unfortunately only for a single viral genotype or subtype, and in most cases this is focused more specifically on blood bank screening and not for routine virological diagnostics. This lack of focus on standardization is one of the hurdles that need to be taken for the in-house developed assays for the 'non-commercially interesting' viral targets.

We have introduced the MagnaPure LC system (Roche Applied Science, Penzberg, Germany) in our laboratory as an open extraction system, initially for the extraction of RNA and DNA from serum and plasma. Combined with real time detection, whether TaqMan technology or NASBA amplification, this enabled us to automatically extract and subsequently detect both RNA and DNA over a large dynamic range in a single clinical sample. To monitor this extraction process for loss or inhibition, we introduced the use of a universally internal viral control, which consists of a complete DNA virus, the non-human seal herpes virus type 1 (PhHV-1). A real time and quantitative TaqMan assay was developed for this seal herpesvirus, which can be grown relatively easily in cell culture. Meanwhile, we also have introduced a universal RNA virus as an internal 


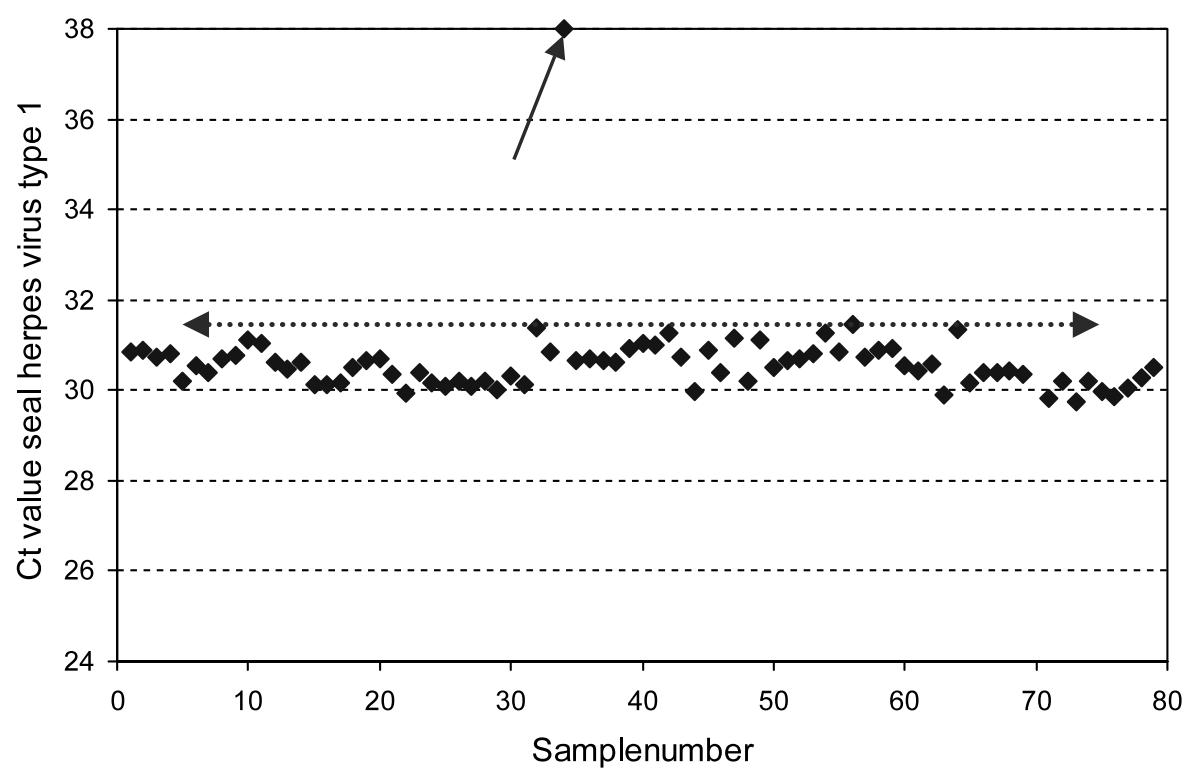

Fig. 1. Data with the cycle threshold $(\mathrm{Ct})$ value of the amplification plot of seal herpes virus type $1(\mathrm{PhHV}-1)$ added at a fixed concentration of approximately 5000-8000 copies per $\mathrm{ml}$ to each clinical. The results of a single experiment are shown, which are imported into a spreadsheet program. The virus was co-extracted using the MagnaPure LC isolation station, and quantified on an ABI7700 sequence detection system, using TaqMan universal reaction mixture (Applied Biosystems, Nieuwerkerk aan de Ijssel, The Netherlands). Primers and probe sequences were: forward primer 5'-GGGCGAATCACAGATTGAATC, reverse primer 5'GCGGTTCCAAACGTACCAA, probe (labeled with TET) 5'-TTTTTATGTGTCCGCCACCATCTGGATC. An amplification product of $89 \mathrm{bp}$ within the $\mathrm{gB}$ gene is generated. The average $\mathrm{Ct}$ value was 30.68 (average from 2359 samples analyzed with this lot number), with a S.D. of 0.9. Samples, in which the $\mathrm{Ct}$ value for the internal control was above 32.5 (average plus 2 S.D.), were repeated (one in this run, see arrow).

control, the Phocine distemper virus. The assumption is that a virus used as universal control behaves more similar in the extraction procedure as the target virus of interest, in contrast to using e.g. a plasmid as internal control. A low and fixed amount of this virus (equal to an amount giving a $\mathrm{Ct}$ value in the real time assay of approximately $30-33$, depending on the lot number used) is added to each clinical sample (in our cases mostly serum or plasma) before the extraction procedure starts. This virus is co-extracted and subsequently amplified in a quantitative manner in a separate tube. This methodology enables to monitor the combined effect of extraction (loss of sample) and amplification (inhibition), and enables to be more confident on the quantitative results generated for the viral target of interest. Also negative results from clinical samples ('no target detected') can therefore be generated with high confidence. The data from the internal control are routinely imported into a spreadsheet program, with defined thresholds to approve or disapprove the final results. A typical example is shown in Fig. 1. Currently, multiplexing of the clinical sample with the internal control is under development. This strategy enables us to monitor every new strategy, new equipment or technology for extraction very rapidly, or enables us to check whether different lot numbers of reagents behave identical (or not). Of course, the assumption is that the amplification efficiency for this universal internal control is within the range of the targets of interest.

Finally, external standards should also be more or less identical to the samples of interest with the same or similar amplification efficiency as the clinical samples. The matrix, in which the external control is extracted (if extracted at all), should be similar compared with the samples of interest. This implies that cloned material as external control might be problematic. 


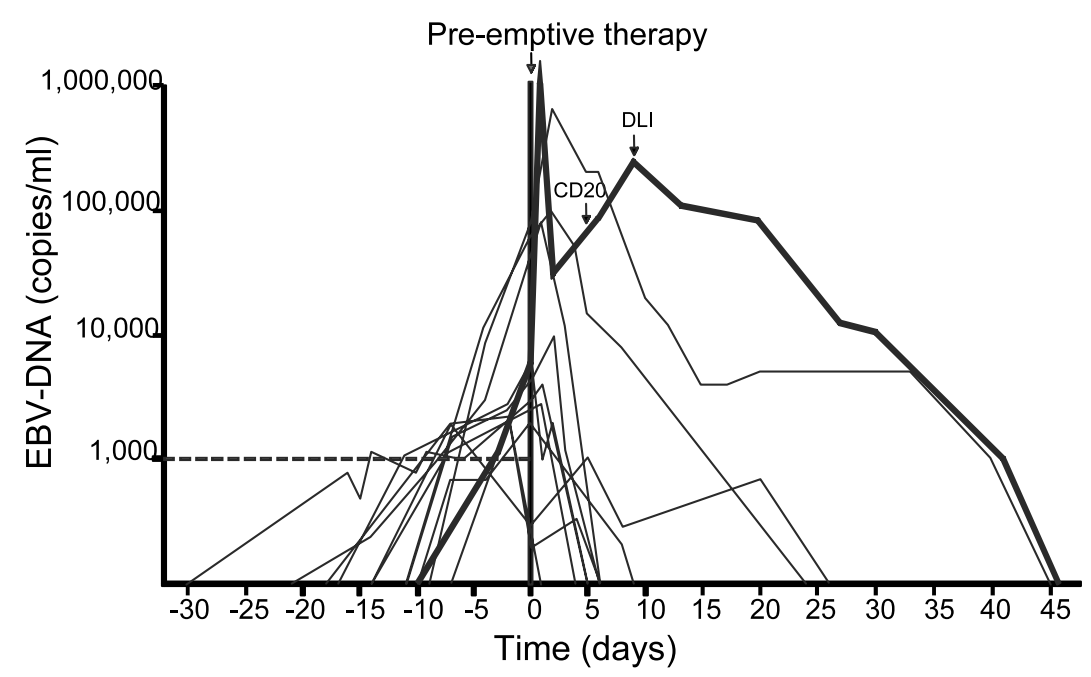

Fig. 2. Pre-emptive anti-B cell immunotherapy for EBV. To monitor patients at risk for EBV related post-transplant lymphoproliferative disease, EBV DNA load was measured on a regular basis. At a level of 1000 copies per ml, the patients were recalled to the hospital and pre-emptive therapy with Rituximab ${ }^{\mathrm{TM}}$ (anti-CD 20 therapy) was initiated. Monitoring was performed on an almost daily basis (five times a week), until the EBV DNA level was twice below the limit of detection (50 copies per ml). If the signal did not decrease rapidly (or an increase was observed), a second infusion with Rituximab ${ }^{\mathrm{TM}}$ or an infusion with donor lymphocytes (DLI) was given (see data represented by the thick line). The initiation of pre-emptive therapy is represented as day 0 . Each line represents an individual patient.

Problems with standards and international standards have already been addressed above, but the conclusion is that absolute quantification is very hard to achieve, and definitely for those viral targets that I would classify as not commercially interesting (at this moment). Only international collaboration, in which diagnostic laboratories should take the lead, will enable to tackle these problems. This does of course not exclude using real time technology to quantify viral targets, since this has shown to give invaluable information on how viruses and their host interact.

\section{Quantitation of viral targets}

With the recent developments of real time technologies, like TaqMan or hydrolysis probes, hybridization probes, and molecular beacons for the detection of amplification products generated by PCR or NASBA technology, the quantification of both RNA and DNA in clinical samples has been much more easier. Also, the availability of ready-to-go reagents for both (RT)-PCR and NASBA is a step forward. Numerous examples of detecting and quantification of viral targets have been published already and the list is growing rapidly (Niesters, 2001). In conclusion, the whole process from isolation up to detection can now be automated, however, for each target the optimal strategy still needs to be established. It has to be determined which threshold values do have clinical importance, or what detection levels need to be reached with this assay.

We have been involved in the development of a pre-emptive strategy to reduce the incidence of Epstein-Barr Virus (EBV) reactivation and the development of EBV related lymphomas (known as post-transplant lymphoproliferative disease; PTLD) in allogeneic T-cell depleted stem cell transplant patients. A TaqMan based assay for the gene encoding the p143 BNRF protein has been developed and used to investigate the incidence of EBV reactivation and the development of EBV related PTLDs (Niesters et al., 2000; van Esser et al., 2001a,b, 2002). Moreover, the assay was and is performed very frequently (between 
three and currently five times a week) enabling to determine the kinetics of EBV replication in our patient population. Several interesting conclusions could be drawn, one of them was that each 10 -fold stepwise increase of EBV DNA measured in plasma, yielded a hazard ratio of $2.9(95 \%$ confidence interval 1.7-4.8) for developing PTLD for those patients receiving a T-cell depleted graft $(P<0.001)$. Furthermore, it was shown that those patients receiving anti-thymocyte globulin (ATG) as part of their conditioning regimen belonged to the population with the highest risk, and not the $\mathrm{T}$ cell depletion itself. The question now was raised at what viral load one should intervene with a pre-emptive antiviral strategy, i.e. to precisely identify those patients at risk. A threshold of 1000 copies per $\mathrm{ml}$ in plasma was chosen to start treatment with Rituximab, a monoclonal antibody directed against CD20, which is the receptor binding-site for EBV. Although this resulted in an over-treatment of patients who have an EBV reactivation and most likely would not develop EBV-PTLD, a reduction of EBV-PTLD incidence and a complete abrogation of PTLD-mortality at 6 months was observed (van Esser et al., 2002). An example of the kinetic pattern observed with EBV DNA measured in plasma is shown in Fig. 2. It can be observed that the EBV DNA viral load can increase very rapidly, making it necessary to perform the real time testing on a regular basis. Monitoring patients at risk, and follow up after the initiation of treatment frequently is thus necessary. An advantage of the isolation of nucleic acids using generic methods is that it also enables to detect several clinically important viruses simultaneously. Definitely in the growing population of immunocompromised patients, this strategy seems to be fruitful. Fig. 3 shows the example of a simultaneous detection of the herpesviruses EBV and human cytomegalovirus (CMV) in a bone marrow transplant patient.

\section{The precise description of the virus}

Once we are able to detect and quantify in principal any virus of interest, the question remains whether the characterization of the isolated or detected virus should be informative for patient management. It has been shown that for the blood borne viruses, the characterization of the virus is becoming more or less a routine practice in clinical virology. For HIV-1, the genotypic resistance pattern, usually obtained by sequencing both the reverse transcriptase and protease gene, generates a lot of information to enable optimal anti-retro-

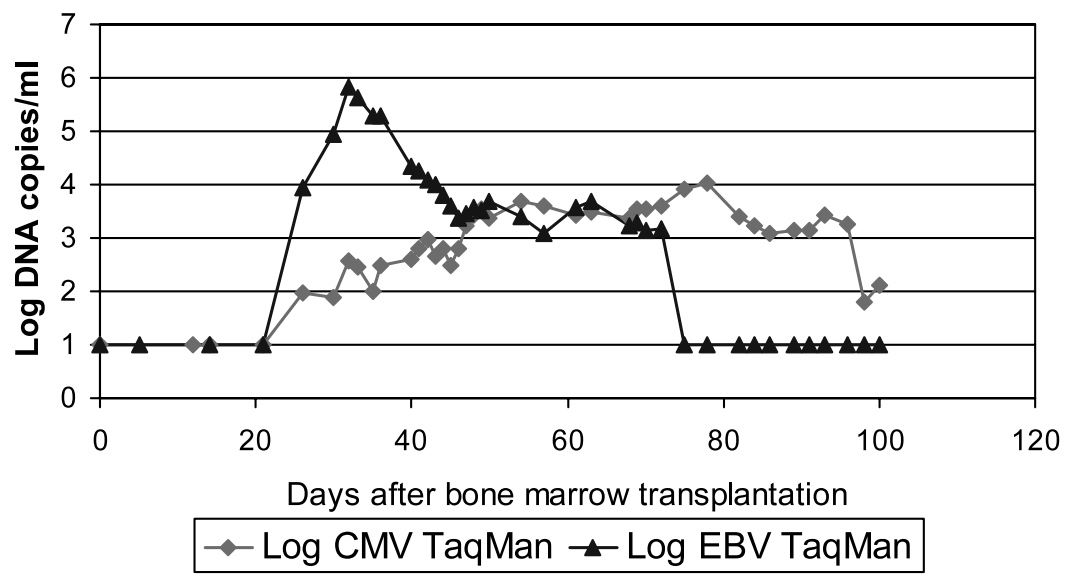

Fig. 3. The simultaneous detection of EBV and human cytomegalovirus (CMV) in a bone marrow transplant patient. Using generic isolation techniques, viral nucleic acids are isolated on a MagnaPure LC isolation station from EDTA plasma samples. Detection of EBV and CMV was performed using real time TaqMan detection on an ABI7700 sequence detection system. To ensure accurate results, a fixed amount of seal herpes virus type 1 was added to the samples before extraction was initiated. As external standards, electron microscopic counted EBV and CMV standards (Advanced Biotechnologies Inc., Columbia, USA) were used. 
viral therapy. This is done mostly in combination with the generation of quantitative RNA data. For the hepatitis $\mathrm{C}$ virus, the genotype is important, combined again with the viral load, for the determination of the duration of therapy using interferon and ribavirin (EASL, 1999). There are a number of technologies to achieve this, but sequencing is in principal the ultimate way of characterization. A disadvantage is that, during antiviral treatment, a mixture of both wild type and variant virus does co-exist. It has been observed that sequencing is not very suitable for the detection of minor populations of variant viruses (Schuurman et al., 1999). Other technologies as reverse hybridization (Stuyver et al., 1997, 2000; Pas et al., 2002) or restriction fragment length polymorphism (RFLP) analysis (Allen et al., 1999; Niesters et al., 2002) might be more suitable, but it should be clear that they are only successful if the sequence changes are known in a specific gene. Again, viral load measurements can be very supportive in searching for new variants.

We have recently identified a new variant in the so-called YMDD motif of the polymerase gene of $\mathrm{HBV}$, in which the methionine was replaced by a serine (Niesters et al., 2002). The development of a new RFLP analysis could determine the dynamics in which both wild type and variant sequences were present during and after antiviral therapy (Fig. 4). It has been estimated that there are approximately 300 million HBV chronic carriers worldwide. The measurement of HBV DNA in serum has become an important tool to identify individuals with high viral replication who might benefit from antiviral therapy, to monitor patients on therapy, and to predict whether antiviral therapy will be successful. The dynamic range in which HBV is detected in patients can be up to ten logs, which immediately implies that current commercially available technologies are unable to

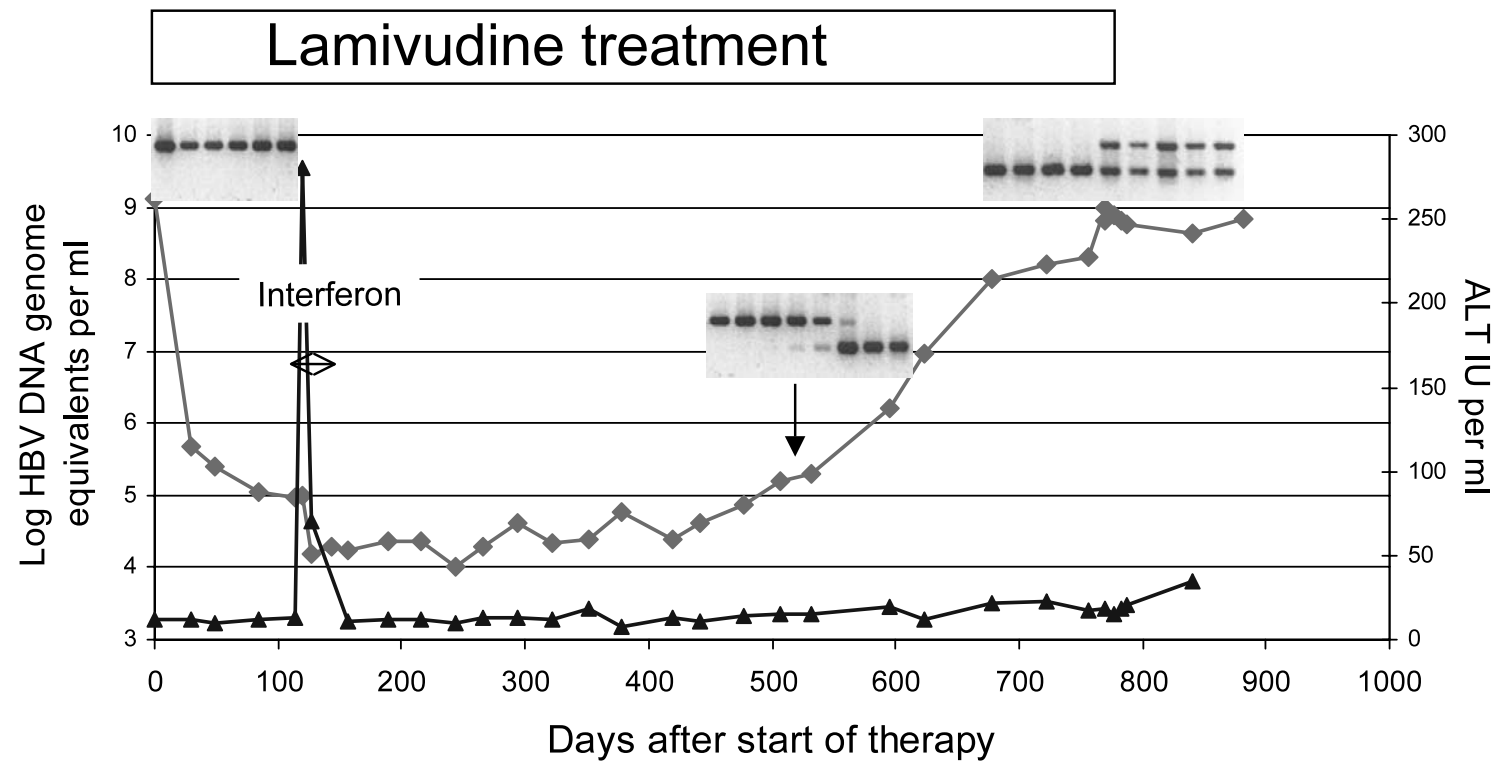

\section{Log HBV DNA $\rightarrow$ ALT}

Fig. 4. Analysis of a patient chronically infected with hepatitis B virus (HBV) during and after antiviral therapy with lamivudine. Close monitoring using alanine aminotransferase (ALT) and HBV DNA values was performed. Once the DNA values increased under antiviral therapy, sequencing analysis identified a new variant (YSDD). A restriction fragment length polymorphism analysis was developed enabling detection of both wild type (120 bp fragment) and variant virus (105 bp fragment). During a 2-week period interferon-alpha was added to the lamivudine treatment, however, an ALT flare was observed and the addition of interferon-alpha was stopped. After end of treatment, both wild type and variant virus were detected simultaneously. For details see Niesters et al. (2002). 
quantify without diluting or concentrating the sample. Real time amplification is thus definitely the technology to use (Pas et al., 2000). With the introduction of new antiviral drugs like Lamivudine $\left\{(-) \quad 2^{\prime}, 3^{\prime}\right.$-dideoxy-3'-thiacytidine $\}$, close monitoring of patients has become increasingly important due to the occurrence of viral resistant strains, or the presence of flares after withdrawal from antiviral therapy (Honkoop et al., 1995, 1997).

\section{Is there still a place for virus culture?}

The implementation of molecular technologies into clinical virology has resulted not only in the improvement of diagnostics for a number of viruses using the quantitative detection of nucleic acids and the monitoring of antiviral therapy, especially for HIV-1, HBV, and HCV, but also in the development of an amplification assay for almost every human virus. Also for those viruses that can be cultured relatively easily, like e.g. HSV types 1 and 2 (Espy et al., 2000). These new molecular technologies do have several advantages, definitely in those settings in which routine virus culture is not available. However, it should also be noted that an improved sensitivity is observed in most instances. The implementation of molecular diagnostics into routine clinical diagnostic virology will proceed and could ultimately replace or reduce virus culture techniques. The implementation of automated extraction and detection technologies, combined with an extensive quality control program, should ultimately convince both clinicians and virologists that molecular diagnostics is a strong cornerstone in clinical virology. The final critical remark often mentioned that not all positive results should have a clinical significance, will be counter-parted by good clinical and epidemiological information, combined with quantitative information on one or more viruses present. However, the ability to exclude viral infections has the advantage that unnecessary therapeutic options are avoided, which inevitably will reduce overall costs for patient care. But we do need financial figures to prove this. Thus with an improved accuracy and sensitivity combined with a more rapid turn around time, these molecular technologies are important for clinical patient care providing information for the best therapeutic options.

There is of course still a need for virus culture, otherwise we will be unable to identify new viruses circulating, like the human metapneumovirus (van den Hoogen et al., 2001), but it is clear that a large transition from virus culture into molecular diagnostics is at hand.

\section{Conclusions}

The availability of open technologies enables not only the routinely isolation of nucleic acids from an increasing number of clinical materials, but also due to the implementation of real time detection systems, the whole process can be performed semi-automatically with quantitative detection of viral RNA and DNA targets. Furthermore, the risk of contamination is minimalized, and the turn-around time to generate results, with minimal handling by personnel, whether positive or negative is becoming shorter. Results can be generated easily within a working day, although often not necessary, and it is expected that in the near future this will be reduced to hours.

The molecular technologies are becoming mature and part of routine clinical virology. But also the home-brew assays do become mature, since standardized reagents and improved quality control programs are enhancing laboratory performance. And most importantly, these standardized reagents are getting cheaper in time, making the discussion on high costs rather obsolete.

One of the greatest advantages however is the ability to detect more positive target sequences in clinical samples. This will give us insight not only in the relation between virus and host, but importantly patients at risk can be treated more specifically. Molecular testing has been rather successful in those areas in which conventional virological techniques did not exists or could be improved. Currently, molecular testing is also available for those targets for which conventional technologies are available. Logistics within the laboratory, prices of assays as well as clinical 
benefit will be the new criteria that make these technological improvements really a part of the new era of a diagnostic setting.

\section{References}

Allen MI, Gauthier J, Deslauriers M, Bourne EJ, Carrick KM, Baldanti F, Ross LL, Lutz MW, Condreay LD. Two sensitive PCR-based methods for detection of hepatitis B virus variants associated with reduced susceptibility to lamivudine. J Clin Microbiol 1999;37:3338-47.

Damen M, Cuypers HT, Zaaijer HL, Reesink HW, Schaasberg WP, Gerlich WH, Niesters HG, Lelie PN. International collaborative study on the second EUROHEP HCV-RNA reference panel. J Virol Methods 1996;58:175-85.

EASL. International Consensus Conference on hepatitis C. Paris, 26-27 February 1999. Consensus statement. J Hepatol 1999;31(Suppl. 1):3-8.

Espy MJ, Uhl JR, Mitchell PS, Thorvilson JN, Svien KA, Wold AD, Smith TF. Diagnosis of herpes simplex virus infections in the clinical laboratory by LightCycler PCR. J Clin Microbiol 2000;38:795-9.

Honkoop P, de Man RA, Heijtink RA, Schalm SW. Hepatitis B reactivation after lamivudine. Lancet 1995;346:1156-7.

Honkoop P, Niesters HG, de Man RA, Osterhaus AD, Schalm SW. Lamivudine resistance in immunocompetent chronic hepatitis B. Incidence and patterns. J Hepatol 1997;26:1393-5.

Mackay IM, Arden KE, Nitsche A. Real-time PCR in virology. Nucleic Acids Res 2002;30:1292-305.

Niesters HG. Quantitation of viral load using real-time amplification techniques. Methods 2001;25:419-29.

Niesters HG, van Esser J, Fries E, Wolthers KC, Cornelissen J, Osterhaus AD. Development of a real-time quantitative assay for detection of Epstein-Barr virus. J Clin Microbiol 2000;38:712-5

Niesters HG, de Man RA, Pas SD, Fries E, Osterhaus AD. Identification of a new variant in the YMDD motif of the hepatitis B virus polymerase gene selected during lamivudine therapy. J Med Microbiol 2002;51:695-9.

Pas SD, Fries E, de Man RA, Osterhaus AD, Niesters HG. Development of a quantitative real-time detection assay for hepatitis B virus DNA and comparison with two commercial assays. J Clin Microbiol 2000;38:2897-901.

Pas SD, de Man RA, Fries E, Osterhaus AD, Niesters HG. The dynamics of mutations in the YMDD motif of the hepatitis $\mathrm{B}$ virus polymerase gene during and after lamivudine treatment as determined by reverse hybridization. J Clin Virol 2002;25:63-71.

Quint WGV, Heijtink RA, Schirm J, Gerlich WH, Niesters HGM. Reliability of methods for hepatitis B virus DNA detection. J Clin Microbiol 1995;33:225-8.

WHO Collaborative Study Group, Saldanha J, Lelie N, Heath A. Establishment of the first international standard for nucleic acid amplification technology (NAT) assays for HCV RNA. Vox Sang 1999;76:149-58.

Saldanha J, Gerlich W, Lelie N, Dawson P, Heermann K, Heath A. An international collaborative study to establish a World Health Organization international standard for hepatitis B virus DNA nucleic acid amplification techniques. Vox Sang 2001;80:63-71.

Schuurman R, Descamps D, Weverling GJ, Kaye S, Tijnagel J, Williams I, van Leeuwen R, Tedder R, Boucher CA, BrunVezinet F, Loveday C. Multicenter comparison of three commercial methods for quantification of human immunodeficiency virus type 1 RNA in plasma. J Clin Microbiol 1996;34:3016-22.

Schuurman R, Demeter L, Reichelderfer P, Tijnagel J, de Groot $\mathrm{T}$, Boucher C. Worldwide evaluation of DNA sequencing approaches for identification of drug resistance mutations in the human immunodeficiency virus type 1 reverse transcriptase. J Clin Microbiol 1999;37:2291-6.

Stuyver L, Wyseur A, Rombout A, Louwagie J, Scarcez T, Verhofstede C, Rimland D, Schinazi RF, Rossau R. Line probe assay for rapid detection of drug-selected mutations in the human immunodeficiency virus type 1 reverse transcriptase gene. Antimicrob Agents Chemother 1997:41:284-91.

Stuyver L, Van Geyt C, De Gendt S, Van Reybroeck G, Zoulim F, Leroux-Roels G, Rossau R. Line probe assay for monitoring drug resistance in hepatitis B virus-infected patients during antiviral therapy. J Clin Microbiol 2000;38:702-7.

Valentine-Thon E, van Loon AM, Schirm J, Reid J, Klapper $\mathrm{PE}$, Cleator GM. European proficiency testing program for molecular detection and quantitation of hepatitis B virus DNA. J Clin Microbiol 2001;39:4407-12.

van den Hoogen BG, De Jong JC, Groen J, Kuiken T, De Groot R, Fouchier RA, Osterhaus AD. A newly discovered human pneumovirus isolated from young children with respiratory tract disease. Nat Med 2001;7:719-24.

van Esser JW, Niesters HG, Thijsen SF, Meijer E, Osterhaus AD, Wolthers KC, Boucher CA, Gratama JW, Budel LM, van der HB, van Loon AM, Lowenberg B, Verdonck LF, Cornelissen JJ. Molecular quantification of viral load in plasma allows for fast and accurate prediction of response to therapy of Epstein-Barr virus-associated lymphoproliferative disease after allogeneic stem cell transplantation. $\mathrm{Br}$ J Haematol 2001a;113:814-21.

van Esser JW, van der HB, Meijer E, Niesters HG, Trenschel R, Thijsen SF, van Loon AM, Frassoni F, Bacigalupo A, Schaefer UW, Osterhaus AD, Gratama JW, Lowenberg B, Verdonck LF, Cornelissen JJ. Epstein-Barr virus (EBV) reactivation is a frequent event after allogeneic stem cell transplantation (SCT) and quantitatively predicts EBVlymphoproliferative disease following T-cell-depleted SCT. Blood 2001b;98:972-8.

van Esser JW, Niesters HG, van der HB, Meijer E, Osterhaus AD, Gratama JW, Verdonck LF, Lowenberg B, Cornelissen JJ. Prevention of Epstein-Barr virus-lymphoproliferative disease by molecular monitoring and preemptive rituximab 
in high-risk patients after allogeneic stem cell transplantation. Blood 2002;99:4364-9.

van Vliet KE, Muir P, Echevarria JM, Klapper PE, Cleator GM, van Loon AM. Multicenter proficiency testing of nucleic acid amplification methods for the detection of enteroviruses. J Clin Microbiol 2001;39:3390-2.
Zaaijer HL, Cuypers HT, Reesink HW, Winkel IN, Gerken G, Lelie PN. Reliability of polymerase chain reaction for detection of hepatitis C virus. Lancet 1993;341:722-4.

Zaaijer HL, ter Borg F, Cuypers HT, Hermus MC, Lelie PN. Comparison of methods for detection of hepatitis B virus DNA. J Clin Microbiol 1994;32:2088-91. 